\title{
The glucose dependent insulinotropic polypeptide response to oral glucose and mixed meals is increased in patients with Type 2 (non-insulin-dependent) diabetes mellitus
}

\author{
I. R.Jones, D. R. Owens, S. Luzio, S. Williams and T.M. Hayes \\ Diabetes Research Unit, Department of Medicine, University of Wales College of Medicine, Cardiff, UK
}

\begin{abstract}
Summary. Considerable disagreement exists regarding the levels of immunoreactive glucose dependent insulinotropic polypeptide in patients with Type 2 (non-insulin-dependent) diabetes mellitus. Glucose dependent insulinotropic polypeptide levels were therefore studied during oral glucose and mixed meal tolerance tests in normal subjects $(n=31)$ and newly presenting previously untreated patients with Type 2 diabetes mellitus $(n=68)$. The tests were performed in random order after overnight fasts and blood samples were taken at $30 \mathrm{~min}$ intervals for $4 \mathrm{~h}$. During the oral glucose tolerance test plasma glucose dependent insulinotropic polypeptide levels increased in the normal subjects from a fasting value of $20 \pm 3 \mathrm{pmol} / 1$ to a peak of $68 \pm 5 \mathrm{pmol} / 1$ at $30 \mathrm{~min}$ and in the Type 2 diabetic patients from a similar fasting level of $27 \pm 3 \mathrm{pmol} / 1$ to a higher peak value of $104 \pm 6 \mathrm{pmol} / 1$ at $30 \mathrm{~min}(p<0.001)$. Glucose dependent insulinotropic polypeptide levels were significantly higher in the diabetic patients compared with the normal subjects from $30-90 \mathrm{~min}$ $(p<0.01-0.001)$ following oral glucose. During the meal tolerance test glucose dependent insulinotropic polypeptide levels
\end{abstract}

increased in the normal subjects from a pre-prandial value of $22 \pm 4 \mathrm{pmol} / 1$ to a peak of $93 \pm 6 \mathrm{pmol} / 1$ at $90 \mathrm{~min}$ and in the Type 2 diabetic patients from a similar basal level of $25 \pm 2 \mathrm{pmol} / 1$ to a higher peak of $133 \pm 7 \mathrm{pmol} / 1$ at $60 \mathrm{~min}$. Glucose dependent insulinotropic polypeptide concentrations were significantly higher in Type 2 diabetic patients compared with the normal subjects at $30 \mathrm{~min}(p<0.001)$, $60 \mathrm{~min}(p<0.01)$ and from $210-240 \mathrm{~min}(p<0.05)$ during the meal tolerance test. The groups were subdivided on the basis of degree of obesity and glucose dependent insulinotropic polypeptide concentrations were still higher in the diabetic subgroups compared with the normal subjects matched for weight. Type 2 diabetes mellitus is associated with an exaggerated glucose dependent insulinotropic polypeptide response to oral glucose and mixed meals which is independent of any effect of obesity.

Key words: Glucose dependent insulinotropic polypeptide, Type 2 (non-insulin-dependent) diabetes mellitus, normal subjects, glucose, insulin, C-peptide.
Glucose dependent insulinotropic polypeptide (GIP) was discovered in 1970 by Brown and Pedersen while investigating the possible existence of a polypeptide of porcine duodenojejunal origin with the biological activity of inhibiting motor activity and acid and pepsin secretion by the canine stomach [1]. In 1973 GIP was shown to stimulate insulin release in man [2], and this observation prompted investigations into a possible role for the hormone in the pathophysiology of diabetes mellitus.

Several studies have investigated the plasma immunoreactive GIP response to oral glucose and to a lesser extent meal tests in patients with diabetes mellitus [3-9]. The results of the investigations are conflicting and there is considerable disagreement regarding both basal and stimulated plasma immunoreactive GIP responses in diabetes mellitus. Several factors contribute to the confusion regarding GIP concentrations observed in both obesity and diabetes mellitus. Different populations have been studied and control subjects have not always been matched for obesity [4], the effect of which remains contentious. The diabetic subjects studied have comprised heterogeneous groups, and patients with Type 2 (non-insulin-dependent) diabetes mellitus have often been treated by diet or even oral hypoglycaemic agents before being studied [3-5]. Different methodologies have also been employed with immunoreactive GIP responses being 
Table 1. Composition of meal tolerance test (MTT). All figures taken from McCance and Widdowson's "The Composition of Foods" by A.A. Paul and D.A.T.Southgate, Fourth revised and extended edition [33]

\begin{tabular}{|c|c|c|c|c|c|c|c|}
\hline Food & $\begin{array}{l}\text { Energy } \\
\text { kcal }\end{array}$ & $\begin{array}{l}\text { Protein } \\
\mathrm{g}\end{array}$ & $\begin{array}{l}\text { Fat } \\
\mathrm{g}\end{array}$ & $\begin{array}{l}\text { Total } \\
\text { CHO } \\
\text { g }\end{array}$ & $\begin{array}{l}\text { Sugars } \\
\mathrm{g}\end{array}$ & $\begin{array}{l}\text { Starch } \\
+ \\
\text { dextrins } \\
\mathrm{g}\end{array}$ & $\begin{array}{l}\text { Diet } \\
\text { fibre }\end{array}$ \\
\hline $15 \mathrm{~g}$ Weetabix & 51 & 1.71 & 0.51 & 10.55 & 0.92 & 9.98 & 1.9 \\
\hline${ }^{\mathrm{a}} 10 \mathrm{gm}$ skimmed milk powder & 35.5 & 3.64 & 0.13 & 5.28 & 5.28 & 0 & 0 \\
\hline $250 \mathrm{ml}$ pineapple juice & 132.5 & 1.0 & 0.25 & 33.5 & 33.5 & $\operatorname{Tr}$ & 0 \\
\hline $50 \mathrm{~g}$ white meat chicken & 71 & 13.25 & 2.0 & 0 & 0 & 0 & 0 \\
\hline Totals & 493.4 & 25.46 & 12.1 & 76.39 & 41.14 & 35.6 & 4.6 \\
\hline Percentage calories & & $20 \%$ & $20 \%$ & $60 \%$ & & & \\
\hline
\end{tabular}

a made up to $200 \mathrm{ml}$ volume with water

measured following a variety of oral glucose loads [3-5] and markedly different test meals [6, 7, 9]. Finally, and perhaps the most important reason for reported differences in GIP responses is that different GIP antisera have been used to measure immunoreactive GIP due primarily to differences in the cross reactivity of the various antisera with human GIP [10-14]. The antisera cross-react with a GIP [15-42] C-terminal fragment which is the region where amino acid differences between porcine and human GIP are found [15]. Another factor which contributes to the different values measured, is the different cross-reactivities of the antisera with the 5 kilo Dalton $(\mathrm{Kd})$ and $8 \mathrm{Kd}$ forms of immunoreactive GIP. The main increase in immunoreactive GIP following both oral glucose and fat is due to an increase in the $5 \mathrm{Kd}$ form of GIP and only small and inconsistent changes in the $8 \mathrm{Kd}$ form are found [14]. Although the $8 \mathrm{Kd}$ component is of importance for the absolute immunoreactive GIP concentration in plasma, it is probably not secreted in sufficient quantities to significantly influence incremental immunoreactive GIP levels following oral nutrients [14]. Another important difference in assay procedures concerns the detection of a high molecular weight component of immunoreactive GIP which elutes in the void-volume on gel filtration of human serum [3]. Void-volume immunoreactive GIP may represent a complex formed by the non-specific binding of GIP to large molecular weight proteins. In some assays void-volume immunoreactive GIP is removed by extraction of plasma before immunoreactive GIP is measured, whereas others use whole plasma [19]. The influence of void-volume immunoreactive GIP in assays not using extraction of plasma is uncertain, but the amount of void-volume immunoreactive GIP varies considerably both within and between subjects [14] even when determined with the same antiserum and may therefore contribute to differences in total immunoreactive GIP measured by the different techniques.

These differences in GIP antisera and assay techniques not only make comparisons between results from different laboratories impossible, but contribute to the confusion in the published data regarding plasma immunoreactive GIP concentrations and responses to different nutrients in patients with Type 2 diabetes mellitus. GIP is released not only during the absorption of glucose $[3,5,8]$ but also during the absorption of fat $[3,11,16]$ and to a lesser extent amino acids [17]. We have previously shown that even in normal subjects glucose tolerance, B-cell secretory function and plasma immunoreactive GIP responses are quite different following the ingestion of oral glucose compared with mixed meals of equivalent carbohydrate content [18].

The aim of this study therefore was to describe the plasma immunoreactive GIP profiles to both oral glucose and standard mixed meals in both normal subjects and patients with Type 2 diabetes mellitus, using a GIP antiserum (R65) specific for the $5 \mathrm{Kd}$ form of immunoreactive GIP [19] which reacts with the extreme C terminal moiety of GIP [20].

\section{Subjects and methods}

Thirty-one normal subjects and 68 newly diagnosed patients previously untreated with Type 2 diabetes mellitus were studied. The normal subjects ( 20 males, 11 females) were aged $24-62$ years (median 38 years) weighed between 48 and $107 \mathrm{~kg}$ (median $76 \mathrm{~kg}$ ) with body mass index (BMI) from 21 to 31 (median 27) and they had no family history of diabetes mellitus. The Type 2 diabetic patients comprised 51 males and 17 females. Their ages ranged from 24-76 years (median 54 years), they weighed between 56 and $118 \mathrm{~kg}$ (median $82 \mathrm{~kg}$ ) and their body mass index varied from 21 to 32 (median 27). All subjects had normal plasma urea and creatinine concentrations and normal liver function tests. The study was approved by the local ethical committee and informed consent was given by each subject.

All subjects were studied on two consecutive days. They were given an oral glucose tolerance test (OGTT) (75 g) or meal tolerance test (MTT) $(500 \mathrm{kcal}-60 \%$ carbohydrate) in random order. The oral glucose challenge during the OGTT consisted of $75 \mathrm{~g}$ glucose dissolved in $200 \mathrm{mls}$ of water. The composition of the MTT is shown in Table 1 . It contained approximately $500 \mathrm{kcal}$ made up of $20 \%$ protein, $20 \%$ fat and $60 \%$ carbohydrate and therefore had a similar carbohydrate content to the OGTT. The subjects were allowed $10 \mathrm{~min}$ to consume the oral glucose or meals. 

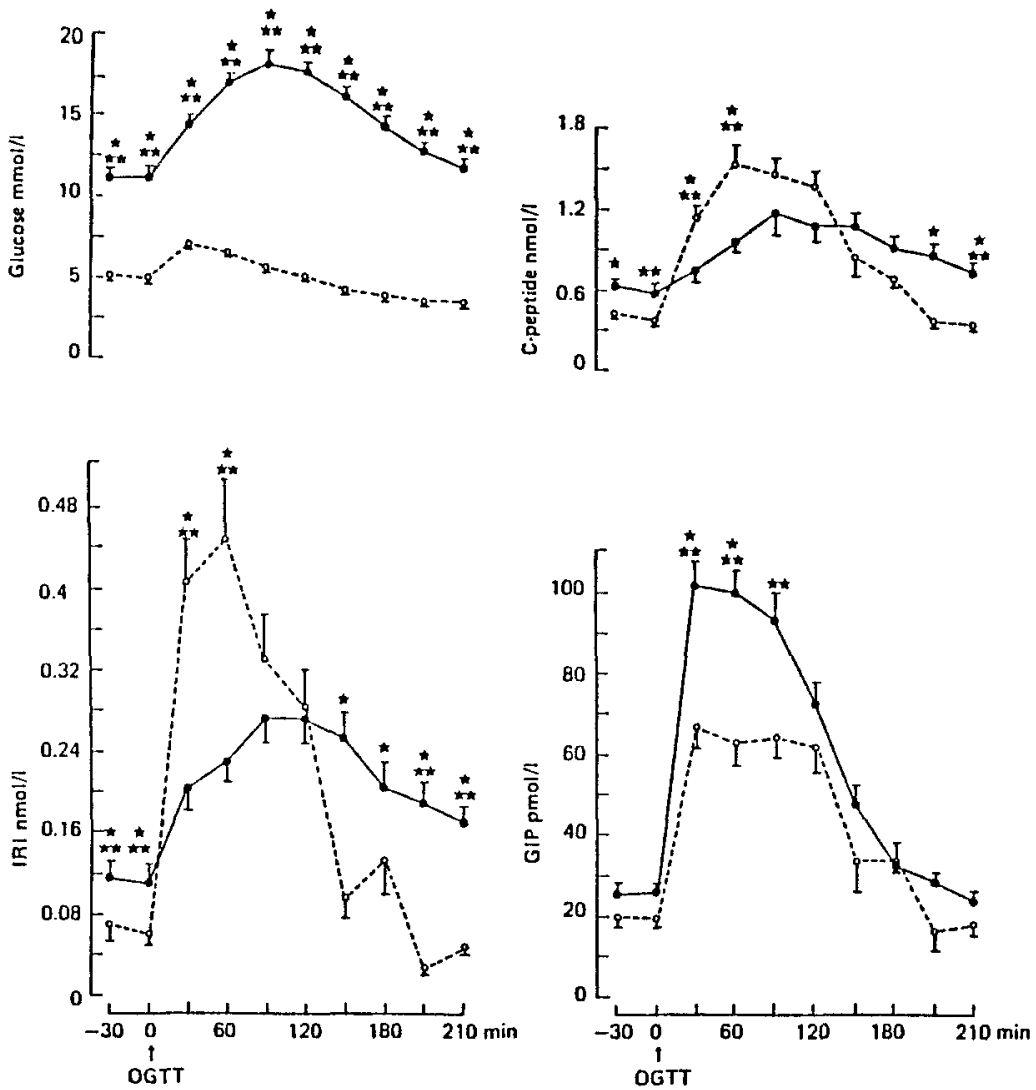

Fig. 1. Oral glucose tolerance test (OGTT: $75 \mathrm{~g}$ ) in normal subjects $(---)(n=31)$ and Type 2 (non-insulin-dependent) diabetic patients (-) $(n=68)$. Mean \pm SEM concentrations of plasma glucose, insulin (IRI), $\mathrm{C}$-peptide and glucose dependent insulinotropic polypeptide (GIP). * $p<0.05 ; * * p<0.001$
After a $10 \mathrm{~h}$ overnight fast the subjects were admitted to a metabolic unit, where they remained on bed-rest throughout the study; smoking was not permitted. An intravenous cannula (Venflon 19G) was inserted into an antecutibal fossa vein and connected with a threeway tap to a slow running infusion of $\mathrm{NaCl}(0.154 \mathrm{mmol} / 1)$. At each sampling time point the $\mathrm{NaCl}$ infusion was stopped and $2 \mathrm{ml}$ of blood was withdrawn and discarded prior to obtaining the sample for analysis. Blood samples were taken at $8.30 \mathrm{~h}$ and immediately prior to the administration of the OGTT or MTT at $09.00 \mathrm{~h}$ and then at $30 \mathrm{~min}$ intervals for $4 \mathrm{~h}$. At each time point plasma glucose, immunoreactive insulin, C-peptide and GIP concentrations were measured.

The blood was taken into fluoride tubes for plasma glucose determination (glucose oxidase), and into lithium-heparin tubes containing 1000 kallikrein inhibitory units of aprotinin (Novo A/S, Bagsvaerd, Denmark) for the determination of insulin [21], C-peptide [22] and immunoreactive GIP levels [14]. All samples were collected on ice, centrifuged at $4^{\circ} \mathrm{C}$ and the supernatant stored at $-20^{\circ} \mathrm{C}$ until assay. The detection limit of immunoreactive insulin was $0.021 \mathrm{nmol} / 1$ and the precision (SD within assay) was $0.009 \mathrm{nmol} / 1$. The detection limit for $C$ peptide was $0.035 \mathrm{nmol} / 1$ and the precision $0.0115 \mathrm{nmol} / 1$. Plasma immunoreactive GIP was measured using the R65 antiserum. Of all the antisera available this has one of the highest cross-reactivities with human GIP [13]. The GIP detection limit was $5 \mathrm{pmol} / 1$ and the precision $1.8 \mathrm{pmol} / 1$.

In order to exclude any effect of obesity, each group was subdivided according to the BMI of the individual subjects. Those with a BMI of $<25$ were classified as lean and those $\geq 25$ as obese.

\section{Statistical analysis}

The results were expressed as means \pm SEM and the significance assessed using the Student's unpaired t-test. A $p$ value of $<0.05$ was considered statistically significant.

\section{Results}

\section{Oral Glucose Tolerance Test in normal subjets $(n=31)$ and Type 2 diabetic patients $(n=68)$}

The mean +SEM concentrations for plasma glucose, insulin, C-peptide and immunoreactive GIP for both the normal subjects and diabetic patients are shown in Fig.1.

In the normal subjects plasma glucose levels increased from a fasting value of $5.2 \pm 0.1 \mathrm{mmol} / 1$ to a peak of $7.6 \pm 0.3 \mathrm{mmol} / 1$ at $30 \mathrm{~min}$. In contrast, the fasting plasma glucose value in the diabetic patients was significantly higher at $11.5 \pm 0.4 \mathrm{mmol} / 1(p<0.001)$ and increased to a higher peak concentration of $19.2 \pm$ $0.6 \mathrm{mmol} / 1$ at $90 \mathrm{~min}(p<0.001)$. Glucose levels were significantly higher in the diabetic patients compared with the normal subjects throughout the study $(p<0.001)$.

During the OGTT in the normal subjects insulin levels increased from a fasting value of $0.061 \pm$ $0.006 \mathrm{nmol} / 1$ to a peak of $0.45 \pm 0.06 \mathrm{nmol} / 1$ at $60 \mathrm{~min}$. In the diabetic patients the fasting insulin level was significantly higher at $0.112 \pm 0.009 \mathrm{nmol} / 1(p<0.001)$. Following the oral glucose load insulin levels increased to a lower and delayed peak value of only $0.281 \pm 0.002 \mathrm{nmol} / 1$ at $90 \mathrm{~min}$. The early insulin levels after the OGTT were significantly lower in the diabetic patients compared with the normal subjects at 30 and $60 \mathrm{~min}(p<0.001)$. The rise in insulin concen- 

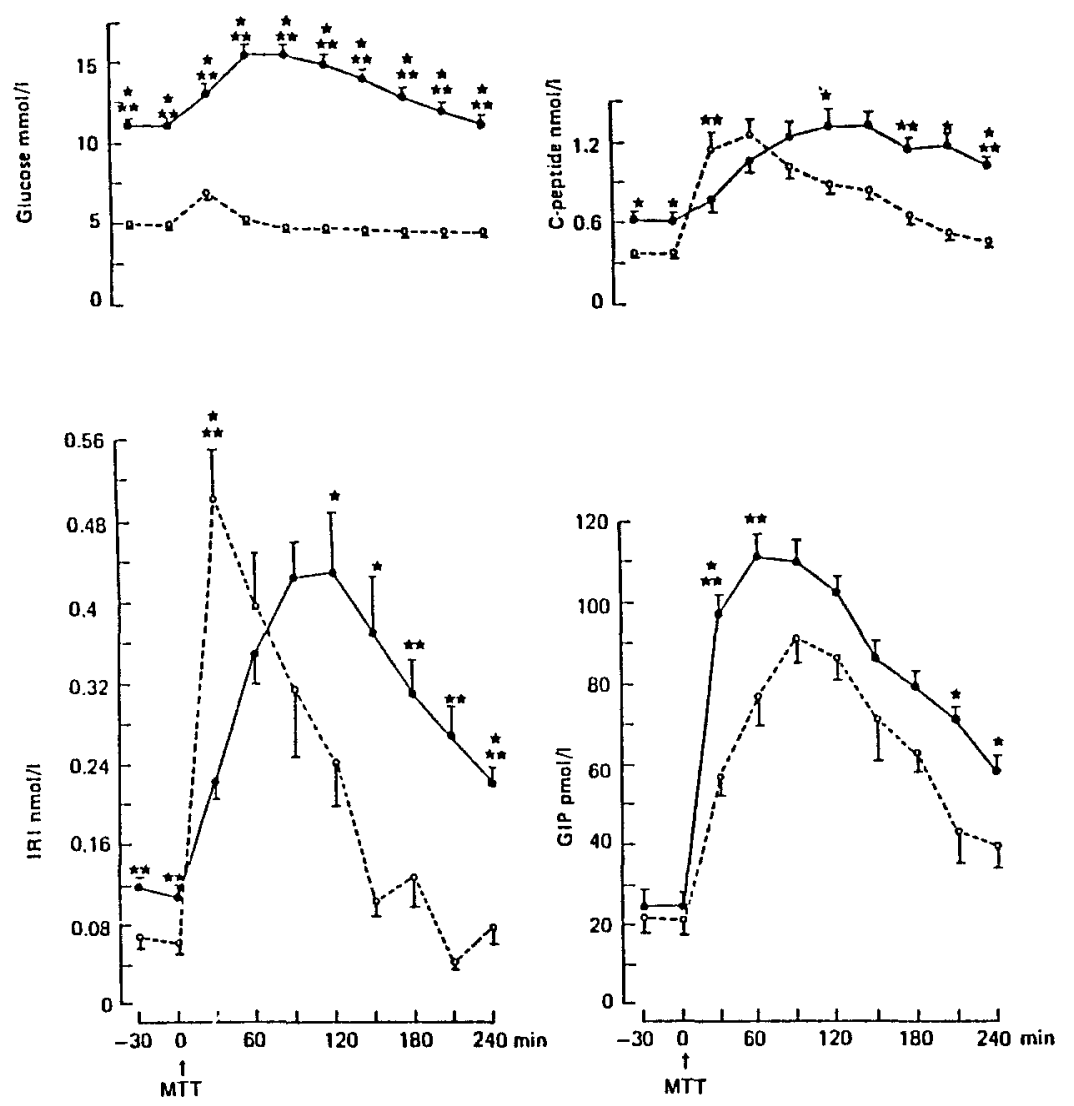

Fig. 2. Meal tolerance test (MTT: $500 \mathrm{kcal}, 60 \%$ CHO) in normal subjects $(---)(n=31)$ and Type 2 (non-insulin-dependent) diabetic patients $(-$ ) $(n=68)$. Mean \pm SEM concentrations of plasma glucose, insulin (IRI), C-peptide and glucose dependent insulinotropic polypeptide (GIP). * $p<0.05$; $* * p<0.01$; *** $p<0.001$

tration in the diabetic patients was more prolonged with the values being significantly higher than those of the normal subjects from 150 to $240 \mathrm{~min}$ $(p<0.05-0.001)$.

C-peptide levels showed a similar pattern to the insulin response. In the normal subjects C-peptide values increased from a fasting level of $0.38 \pm$ $0.02 \mathrm{nmol} / 1$ to a peak value of $1.61 \pm 0.13 \mathrm{nmol} / 1$ at $60 \mathrm{~min}$. In the diabetic patients the fasting C-peptide concentration was significantly higher at $0.59 \pm$ $0.04 \mathrm{nmol} / 1(p<0.01)$, and increased to a lower peak value of $1.26 \pm 0.17 \mathrm{nmol} / 1$ at $90 \mathrm{~min}$. The C-peptide levels in the diabetic patients were significantly lower at $30 \mathrm{~min}(p<0.01)$ and $60 \mathrm{~min}(p<0.001)$. Subsequently the levels remained elevated longer in the diabetic patients the difference reaching significance towards the end of the study at $210 \min (p<0.05)$ and $240 \min (p<0.001)$.

Fasting immunoreactive GIP levels were similar in the two groups. In the normal subjects plasma immunoreactive GIP values increased from a fasting level of $20.2 \pm 3.3 \mathrm{pmol} / 1$ to a peak of $68.5 \pm 5.2 \mathrm{pmol} / \mathrm{l}$ at $30 \mathrm{~min}$. In the diabetic patients immunoreactive GIP values increased from $27.6 \pm 2.8 \mathrm{pmol} / \mathrm{l}$ to a higher peak concentration of $103.8 \pm 6.3 \mathrm{pmol} / 1$ at $30 \mathrm{~min}$ $(p<0.001)$. Immunoreactive GIP levels were significantly greater in the Type 2 diabetic patients compared with the normal subjects from $30-90 \mathrm{~min}$ $(p<0.01-0.001)$ during the OGTT.

\section{Meal tolerance test in normal subjects $(n=31)$ and Type 2 diabetic patients $(n=68)$}

The mean \pm SEM plasma glucose, insulin, C-peptide and immunoreactive GIP concentration for the normal subjects and diabetic patients during the MTT are illustrated in Fig. 2.

During the MTT in the normal subjects the plasma glucose levels increased from a fasting value of $5.0 \pm 0.1 \mathrm{mmol} / 1$ to a peak level of $7.24 \pm 0.2 \mathrm{mmol} / 1$ at $30 \mathrm{~min}$. In the diabetic patients the fasting glucose concentration was significantly higher at $11.2 \pm 0.2 \mathrm{mmol} / 1$ $(p<0.001)$ and increased to a higher peak value of $15.8 \pm 0.48 \mathrm{mmol} / 1$ at $60 \mathrm{~min}(p<0.001)$. Glucose values were significantly higher in the diabetic patients compared with the normal subjects throughout the study period $(p<0.001)$.

During the MTT insulin levels in the normal subjects increased from a pre-prandial value of $0.062 \pm$ $0.008 \mathrm{nmol} / 1$ to a peak level of $0.509 \pm 0.04 \mathrm{nmol} / 1$ at $30 \mathrm{~min}$. In the diabetic patients the basal insulin concentration was significantly higher at $0.106 \pm$ $0.009 \mathrm{nmol} / 1(p<0.05)$. However, following the mixed meal and insulin levels it increased more slowly and was significantly lower in the diabetic patients after $30 \mathrm{~min}$ at only $0.22 \pm 0.016 \mathrm{nmol} / 1 \quad(p<0.001)$ and reached a delayed peak of $0.439 \pm 0.05 \mathrm{nmol} / 1$ at $120 \mathrm{~min}$. Although the early insulin response was poor in the diabetic patients compared with the normal sub- 

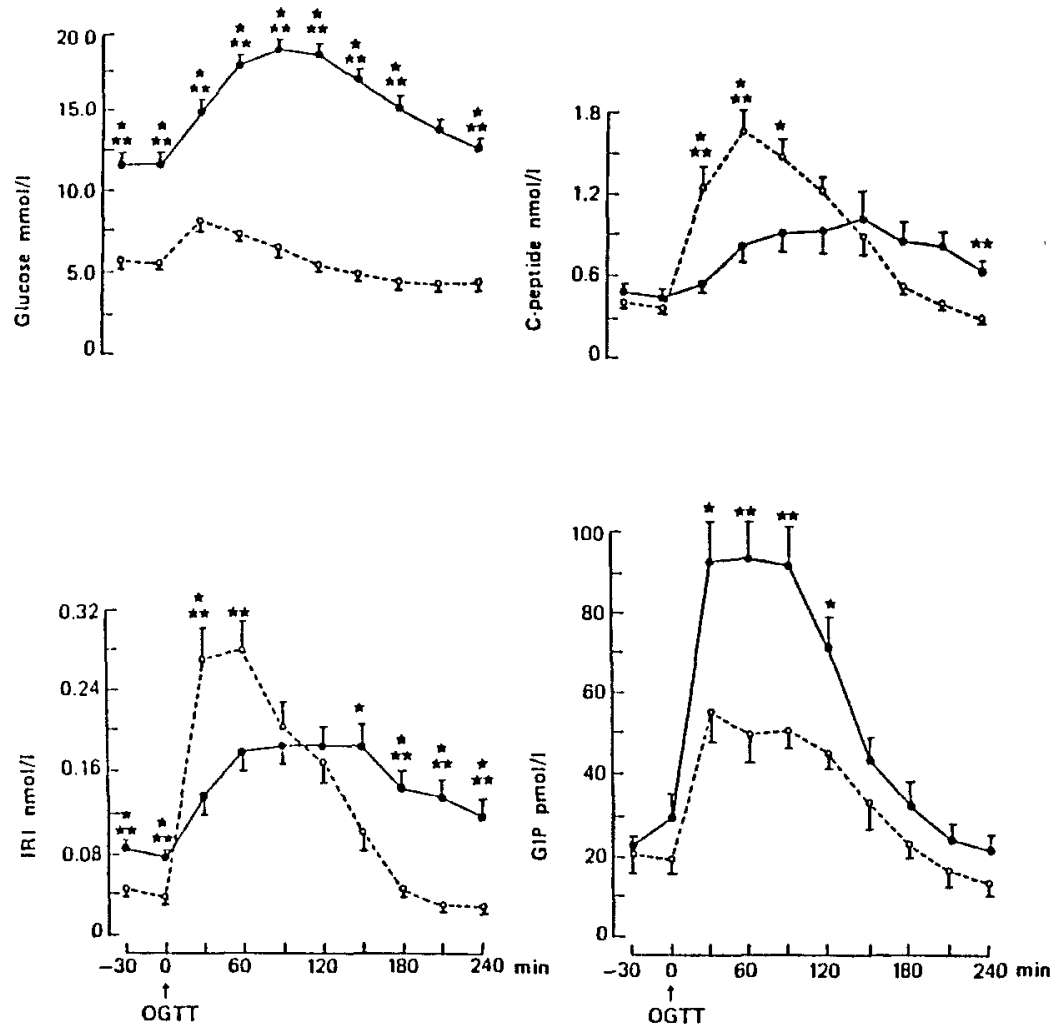

Fig. 3. Oral glucose tolerance test (OGTT: $75 \mathrm{~g}$ ) in lean normal subjects $(---)(n=14)$, Body mass index $(\mathrm{BMI})<25)$ and lean Type 2 diabetic patients $(-)$ $(n=27, \mathrm{BMI} \geq 25)$. Mean \pm SEM concentrations of plasma glucose, insulin (IRI), C-peptide and glucose dependent insulinotropic polypeptide (GIP). $* p<0.05$; ** $p<0.01$; *** $p<0.001$

jects, the rise was more sustained in the diabetic patients and the plasma insulin levels were significantly higher from 120 to $240 \mathrm{~min}$ ( $p<0.05-0.001$ ).

C-peptide levels in the normal subjects increased during the MTT from $0.39 \pm 0.03 \mathrm{nmol} / 1$ to a peak value of $1.32 \pm 0.11 \mathrm{nmol} / 1$ at $60 \mathrm{~min}$. In the diabetic patients the fasting C-peptide concentration increased more slowly to a delayed peak value of $1.39 \pm$ $0.13 \mathrm{nmol} / 1$ at $150 \mathrm{~min}$. The early C-peptide response was also lower in the diabetic patients compared with the normal subjects, but later reached higher values in the diabetic patients at $120 \mathrm{~min}$ and from 180 to $240 \min (p<0.05-0.001)$.

Pre-prandial plasma immunoreactive GIP levels were similar in the two groups. In the normal subjects immunoreactive GIP levels increased from a fasting level of $22.0 \pm 4.0 \mathrm{pmol} / 1$ to a peak of $92.9 \pm 5.9 \mathrm{pmol} / 1$ at 90 min. In the diabetic patients immunoreactive GIP values increased from $25.4 \pm 2.4 \mathrm{pmol} / 1$ to a higher peak concentration of $113.4 \pm 6.8 \mathrm{pmol} / 1$ at $60 \mathrm{~min}$ $(p<0.001)$. Immunoreactive GIP levels were significantly higher in the diabetic patients compared with the normal subjects in response to the MTT at $30 \mathrm{~min}$ $(p<0.001), 60 \mathrm{~min}(p<0.01)$ and from 210 to $240 \mathrm{~min}$ $(p<0.05)$.

\section{Oral glucose tolerance test in lean normal subjects $(n=14)$ and lean Type 2 diabetic patients $(n=27)$}

The mean \pm SEM plasma glucose, insulin C-peptide and immunoreactive GIP concentrations are shown in Fig.3. As in the whole group, glucose values and fasting insulin concentrations were significantly higher in the lean diabetic patients. Insulin and C-peptide levels rose more slowly in the diabetic patients to delayed and lower peak values $(p<0.001)$, but the rise was more sustained becoming significantly higher from $180-240 \mathrm{~min}$ $(p<0.001)$.

Fasting immunoreactive-GIP levels were similar in each group. Immunoreactive GIP values increased in the lean normal subjects from a fasting level of $19.4 \pm 5.6 \mathrm{pmol} / \mathrm{l}$ to a peak of $55.6 \pm 7.0 \mathrm{pmol} / 1$ at $30 \mathrm{~min}$ and in the lean diabetic patients from $31.0 \pm 5.7 \mathrm{pmol} / 1$ to a greater level of $93.6 \pm 9.2 \mathrm{pmol} / 1$ at $60 \mathrm{~min}(p<0.01)$. Immunoreactive GIP levels were significantly higher in the lean diabetic patients from $30-90 \min (p<0.05-0.01)$.

\section{Meal tolerance test in lean normal subjects $(n=14)$ and lean Type 2 diabetic patients $(n=27)$}

The mean \pm SEM plasma glucose, insulin, C-peptide and immunoreactive GIP concentrations are illustrated in Fig. 4.

Glucose values and B-cell response showed a similar pattern during the MTT as they had following the OGTT. Pre-prandial immunoreactive GIP levels were similar in both groups. In the lean normal subjects immunoreactive GIP levels increased from a fasting value of $21.2 \pm 3.7 \mathrm{pmol} / \mathrm{l}$ to a peak of $91.6 \pm 13.7 \mathrm{pmol} / 1$ at $90 \mathrm{~min}$. In the lean diabetic patients immunoreactive GIP values increased from a pre-prandial concentration of $27.1 \pm 3.8 \mathrm{pmol} / \mathrm{l}$ to a higher peak of 



Fig.4. Meal tolerance test (MTT: $500 \mathrm{kcal}, 60 \%$ $\mathrm{CHO})$ in lean normal subjects (- - $)(n=14$, Body mass index $(\mathrm{BMI})<25)$ and lean Type 2 (non-insulindependent) diabetic patients (- $)(n=27$, $\mathrm{BMI} \geq 25$ ). Mlean \pm SEM concentrations of plasma glucose, insulin (IRI), C peptide and glucose dependent insulinotropic polypeptide (GIP). ${ }^{*} p<0.05$; ** $p<0.01 ; * * * \quad p<0.001$
Fig.5. Oral glucose tolerance test (OGTT: $75 \mathrm{~g}$ ) in obese normal subjects $(--+)(n=17$, Body mass index $(B M I)<25)$ and obese Type 2 (non-insulin-dependent) diabetic patients $(\longrightarrow)(n=41, \mathrm{BMI} \geq 25)$. Mean \pm SEM concentrations of plasma glucose, insulin (IRI), Cpeptide and glucose dependent insulinotropic polypeptide (GIP). ${ }^{*} p<0.05 ;{ }^{* *} p<0.01{ }^{* * *} p<0.001$ 

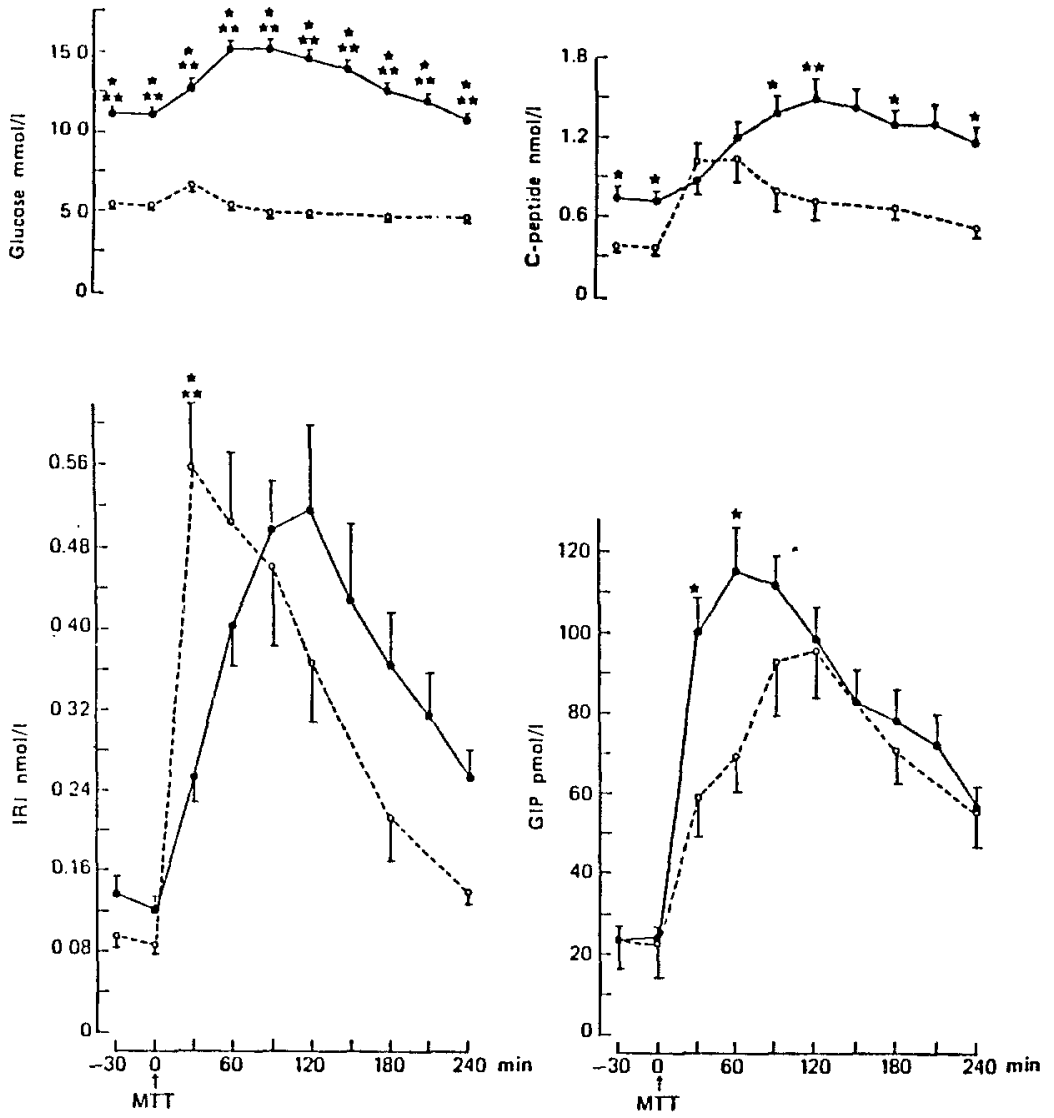

Fig. 6. Meal tolerance test (MTT: $500 \mathrm{kcal}, 60 \%$ carbohydrate) in obese normal subjects $(-\cdots)(n=17$, Body mass index $(\mathrm{BMI})<25)$ and obese Type 2 diabetic patients ( -$)(n=41, \mathrm{BMI} \geq 25)$. Mean \pm SEM concentrations of plasma glucose, insulin (IRI), C-peptide and glucose dependent insulinotropic polypeptide (GIP). * $p<0.05 ; * * p<0.01$; $* * * * 0.001$

$108.9 \pm \mathrm{pmol} / 1$ at $90 \mathrm{~min}$. Post-prandial immunoreactive GIP levels were significantly higher in the lean diabetic patients at $30 \mathrm{~min}(p<0.05), 60 \mathrm{~min}(p<0.01)$, $120 \mathrm{~min}(p<0.05)$ and from $180-240 \mathrm{~min}(p<0.05-$ $0.001)$.

\section{Oral glucose tolerance test in obese normal subjects $(n=17)$ and obese Type 2 diabetic patients $(n=41)$}

Mean \pm SEM plasma glucose, insulin, C-peptide and immunoreactive GIP concentrations are shown in Fig. 5.

Glucose, insulin and C-peptide concentrations showed a similar pattern in the obese group as previously described for lean subjects. Basal immunoreactive GIP levels were again similar in the two groups. Immunoreactive GIP levels increased in the obese normal subjects from a fasting value of $20.3 \pm 5.1 \mathrm{pmol} / 1$ to a peak concentration of $78.7 \pm 6.2 \mathrm{pmol} / 1$ at $30 \mathrm{~min}$ and in the obese diabetic patients from a fasting level of $25.4 \pm 2.6 \mathrm{pmol} / 1$ to a higher peak of $110.8 \pm 8.0 \mathrm{pmol} / 1$ at $30 \mathrm{~min}(p<0.05)$. The immunoreactive GIP concentration remained higher in the obese diabetic patients at $60 \mathrm{~min}(p<0.005)$.

\section{Meal tolerance test in obese normal subjects $(n=17)$ and obese Type 2 diabetic patients $(n=41)$}

Mean \pm SEM plasma glucose, insulin, C-peptide immunoreactive GIP concentrations are illustrated in Fig. 6.
Differences in glucose values and B cell secretion were similar to those previously described for the other subgroups as were changes in immunoreactive GIP concentrations. Pre-prandial immunoreactive GIP levels were virtually identical in the obese normal and obese diabetic subjects. The peak post-prandial immunoreactive GIP level was higher in the obese diabetic patients at $117.1 \pm 9.9 \mathrm{pmol} / 1$ compared with a peak $97.2 \pm 11.8 \mathrm{pmol} / 1$ in the obese normal subjects $(p<0.05)$. The early rise in the immunoreactive GIP levels was greater in the diabetic patients and was significantly higher at $30 \mathrm{~min}(p<0.05)$.

\section{Discussion}

Fasting plasma immunoreactive GIP concentrations were similar in the normal subjects and Type 2 diabetic patients, whereas, endogenously stimulated immunoreactive GIP levels were significantly greater in the diabetic patients following both oral glucose and mixed meals. The difference in plasma immunoreactive GIP response in the patients with Type 2 diabetes mellitus was maximal during the early part of the oral carbohydrate tolerance tests being significantly greater from 30 to 90 min during the OGTT and from 30-60 min during the MTT. Following the mixed meals immunoreactiveGIP levels were higher throughout the study in the diabetic patients and this difference remained at 210 and $240 \mathrm{~min}$. 
The association between obesity and an increased immunoreactive GIP response is still controversial. Some studies have described normal levels in obesity $[9,23]$, but others have reported that excess nutrient ingestion leads to an increased immunoreactive GIP response [24], and exaggerated immunoreactive GIP levels have been observed following mixed meals $[25,26]$. The group of patients with diabetes mellitus in this study were slightly more obese than the normal control subjects and therefore, to exclude any compounding effect of obesity, the two groups were subdivided into lean and obese subjects depending on their body mass index. On comparing the lean diabetic patients with the lean normal subjects the exaggerated immunoreactive GIP response observed in the whole group was still present following both the oral glucose and mixed meals. The obese normal subjects have previously been found to have an exaggerated immunoreactive GIP response compared with lean normal subjects [27], but when compared with the obese diabetic patients the immunoreactiveGIP levels were increased even further in the diabetic group following both glucose and meals, confirming the association between the diabetes and the exaggerated immunoreactive GIP response. Endogenously stimulated immunoreactive GIP concentrations are therefore increased in Type 2 diabetes mellitus per se and this is independent of any possible effect of obesity.

Increased stimulated immunoreactive GIP responses in diabetes mellitus have been previously described by some groups $[3,5,8]$ while others have found increased fasting and stimulated concentrations of immunoreactive GIP [4]. In complete contrast further studies have found normal or even decreased immunoreactive GIP responses in diabetic patients $[6,7,9]$. We believe that the main reasons for the conflicting immunoreactive GIP responses described concerns the use of different GIP antisera, assay methodologies and heterogeneity of the population groups studied.

GIP antisera all cross-react with the 15-42 C-terminal fragment of the GIP molecule, which is the region where structural differences between porcine and human GIP are found [15]. Various antisera have marked differences in cross-reactivity with human GIP [12-14], resulting in wide variation in plasma immunoreactive GIP concentrations measured with different GIP antisera [10, 11]. GIP is present in plasma in $5 \mathrm{Kd}$ and $8 \mathrm{Kd}$ forms and the various antisera crossreact differently with the two forms. Although the $8 \mathrm{Kd}$ component may influence the absolute immunoreactive GIP concentration it probably does not significantly alter endogenously stimulated incremental immunoreactive GIP values, as changes in the $8 \mathrm{Kd}$ form are small and inconsistent and the main increase in immunoreactive GIP following both oral glucose and fat is due to an increase in the $5 \mathrm{Kd}$ form [14]. Plasma immunoreactive GIP levels in this study were all measured with an antiserum (R65) that of all the antisera available has one of the highest cross-reactivities with the $5 \mathrm{Kd}$ form of GIP [13]. Antibodies that detect the $8 \mathrm{Kd}$ form would clearly influence the total GIP mainly in the basal state and its contribution to total concentration measured would decrease in the post-prandial state. Increased fasting immunoreactive GIP concentrations in diabetes mellitus were demonstrated using an antiserum that also detects variable amounts of the $8 \mathrm{Kd}$ form [4], the significance of which remains uncertain. Another factor contributing to the variability in results found, is the immunoreactive GIP detected in the void volume. This possibly represents a complex formed by the non-specific binding of GIP to large molecular weight proteins. Void volume immunoreactive GIP has been shown to vary enormously both within and between subjects [14], and could contribute significantly to total immunoreactive GIP concentrations measured in assays using unextracted plasma. This would make differences in biologically active GIP more difficult to demonstrate when comparing different groups, and may contribute to the failure of some studies to demonstrate a difference between immunoreactive GIP response in normal subjects and patients with diabetes mellitus.

Other factors probably contributing to the variability of immunoreactive GIP responses observed are the heterogeneity of patient studies, and the use of a variety of oral glucose loads [3-5] and markedly different test meals $[6,7,9]$ to stimulate GIP release. Patients with Type 2 diabetes mellitus are a heterogeneous group anyway but this has often been further complicated previously by not matching for obesity [4] and studying patients that had been treated by diet and oral hypoglycaemic agents [3-5]. We therefore only studied patients at the time of diagnosis before they were given any dietary advice or oral hypoglycaemic therapy. In addition to having an exaggerated immunoreactive GIP response the Type 2 diabetic patients were characterized by basal hyperinsulinaemia associated with a poor and delayed B-cell response to both oral glucose and meal tests when compared with the normal subjects. The rise in insulin and C-peptide concentrations in the diabetic patients was however more prolonged and resulted in significantly higher levels towards the end of the $4 \mathrm{~h}$ study periods.

The mechanism for the increased immunoreactive GIP response in the diabetic patients is not clear. It is possible that the early increase in plasma immunoreactive GIP to significantly higher levels in the diabetic patients results from a lack of negative feedback by insulin, the concentration of which is relatively low during the early post-prandial period. A negative feedback by insulin in GIP release has, however, only been described following fat stimulated immunoreactive GIP release and not glucose stimulated immunoreactive GIP release [26]. The increased immunoreactive 
GIP response in the diabetic patients was present not only during the meals which did contain a significant quantity of fat, but also following the oral glucose which makes a lack of negative feedback by insulin an unlikely explantation. It has been reported that C-peptide may not be biologically inactive and may have an inhibitory effect on GIP release [28]. The low early Cpeptide concentrations in the diabetic patients would be consistent with this hypothesis, although, this reported role for $\mathrm{C}$-peptide has never been confirmed. GIP release is also influenced by the autonomic nervous system $[26,29,30]$. The diabetic patients were all newly diagnosed and therefore a significant abnormality of the autonomic nervous system is an unlikely explantation for the increased immunoreactive GIP levels. A significant proportion of the diabetic patients, however, had background retinopathy $(18 \%)$ indicating that in many of them the disease had probably been present for some time prior to diagnosis. Autonomic function tests were not formally performed on these patients and although it is still unlikely, the possibility of autonomic dysfunction contributing to the exaggerated immunoreactive-GIP response cannot be totally discounted.

Whatever the mechanism of the increased immunoreactive GIP concentrations in Type 2 diabetes mellitus its pathophysiological significance is even less clear. It is possible that the enhanced GIP response in Type 2 diabetes is a compensatory mechanism attempting to improve the failing B-cell function particularly during the early post-prandial period. The overall effect of increased immunoreactive GIP levels on insulin secretion in Type 2 diabetes mellitus, however, is likely to be small as Type 2 diabetic patients have been shown to have a reduced incretin effect [34] and their B cells are less sensitive to the exogenous infusion of porcine GIP [35].

In conclusion, Type 2 diabetes mellitus is associated with normal fasting immunoreactive GIP concentrations but an exaggerated immunoreactive GIP response to both oral glucose and mixed meals.

Acknowledgements. The authors wish to thank Dr. A.J. Moody Novo Research Insitute, Copenhagen, Denmark, for the generous supply of glucose dependent insulinotropic antiserum (R65); and Mrs. K. Shewey, Mrs. D.J.Thomas and Mrs. C. Harling for secretarial assistance.

\section{References}

1. Brown JCL, Pedersen RA (1970) A multiparameter study on the action of preparations containing cholecystokinin - pancreozymin. Scand J Gastroenterol 5: 537-541

2. Dupre J, Ross SA, Watson D, Brown JC (1973) Stimulation of insulin secretion by gastric inhibitory polypeptide in man. J Clin Endocrinol Metab 37: 826-828

3. Brown JC, Dryburgh JR, Ross SA, Dupre J (1975) Identification and actions of gastric inhibitory polypeptide. Recent Prog Horm Res 31:487-532

4. Crockett SE, Mazzaferri EL, Cataland S (1976) Gastric inhibitory polypeptide (Glucose dependent insulinotropic polypeptide) in maturity onset diabetes mellitus. Diabetes 25:931-935

5. Ross SA, Brown JC, Dupre J (1977) Hypersecretion of gastric inhibitory polypeptide following oral glucose in diabetes mellitus. Diabetes 26: 525-529

6. May JM, Williams RH (1978) The effect of endogenous gastric inhibitory polypeptide on glucose induced insulin secretion in mild diabetes. Diabetes 27: 849-855

7. Krarup T, Madsbad S, Moody AJ, Regeur L, Faber OK, Holst JJ, Sestoft L (1983) Diminished immunoreactive gastric inhibitory polypeptide response to a meal in newly diagnosed type 1 (insulin-dependent) diabetes. J Clin Endocrinol Metab 56: 1306-1312

8. Salera M, Giacomoni P, Pironi L, Cormia G, Capella M, Marini A, Benfenate F, Miglioli M, Barbara L (1982) Gastric inhibitory polypeptide release after oral glucose: relationship to glucose intolerance, diabetes mellitus and obesity. J Clin Endocrinol Metab 55:329-336

9. Service FJ, Rizza RA, Westland RE, Hall LD, Gerich JE, Go VLW (1984) Gastric inhibitory polypeptide in obesity and diabetes mellitus. J Clin Endocrinol Metab 58: $1133-1140$

10. Sarson DL, Bryant MG, Bloom SR (1980) A radioimmunoassay of gastric inhibitory polypeptide in human plasma. J Endocrinol 85: $487-496$

11. Cleastor JGM, Gourlay RH (1975) Release of immunoreactive gastric inhibitory polypeptide (immunoreactive-glucose dependent insulinotropic polypeptide) by oral ingestion of food substances. Am J Surg 130: 128-135

12. Jorde R, Burhol PG, Schultz TB (1983) Fasting and post-prandial plasma glucose dependent insulinotropic polypeptide values in man measured with seven different antisera. Regul Pep 7: $87-94$

13. Krarup T, Holst JJ (1984) The heterogeneity of gastric inhibitory polypeptide in porcine and human gastrointestinal mucosa evaluated with five different antisera. Regul Pep 9:35-46

14. Krarup T, Holst JJ, Larsen KL (1985) Responses and molecular heterogeneity of immunoreactive-glucose dependent insulinotropic polypeptide after intraduodenal glucose and fat. Am J Physiol 249: E195-200

15. Moody AJ, Thim L, Valverde I (1984) The isolation and sequencing of human gastric inhibitory polypeptide (glucose dependent insulinotropic polypeptide) FEBS Letters 172: 142-148

16. Falko JM, Crockett SE, Cataland S, Mazzaferri EL (1975) Gastric inhibitory polypeptide (glucose dependent insulinotropic polypeptide) stimulated by fat ingestion in man. J Clin Endocrinol Metab 41: 260-265

17. Thomas FB, Mazzaferri EL, Crockett SE, Makhjian HS, Gruemer HD, Cataland S (1976) Stimulation of secretion of gastric inhibitory polypeptide and insulin by intraduodenal amino acid perfusion. Gastroenterology 70:523-527

18. Jones IR, Owens DR, Luzio S, Davies C.J, Hayes TM (1983) The relationship between carbohydrate tolerance and differential hepatic extraction of insulin in response to serial glucose and meal tolerance tests in normal subjects. Diabetologia 25: 168 (Abstract)

19. Krarup T (1988) Immunoreactive gastric inhibitory polypeptide. Endocrine Reviews 9: 122-134

20. Moody AJ, Damm Jorgensen K, Thim L (1981) Structure function relationships in porcine glucose dependent insulinotropic polypeptide. Diabetologia 21: 306 (Abstract)

21. Heding LG (1972) Determination of total serum insulin (immunoreactive insulin) in insulin treated diabetic patients. Diabetologia 8: 260-266

22. Heding LG (1975) Radioimmunological determination of human C peptide in serum. Diabetologia 11:541-548

23. Sarson DL, Kopelman PG, Besterman HS, Pilkington TRE, Bloom SR (1983) Disparity between glucose dependent insulinotropic polypeptide and insulin responses in obese man. Diabetologia $25: 386-391$ 
24. Hampton SM, Kwasowski P, Tan K, Morgan LM, Marks V (1983) Effect of pretreatment with a high fat diet on the gastric inhibitory polypeptide and insulin responses to oral triolein and glucose in rats. Diabetologia 24: 278-281

25. Creutzfeldt W, Ebert R, Willms B, Frerichs H, Brown JC (1978) Gastric inhibitory polypeptide (glucose dependent insulinotropic polypeptide) and insulin in obesity: increased response to stimulation and defective feedback control of serum levels. Diabetologia 14: $15-24$

26. Creutzfeldt W (1979) The incretin concept today. Diabetologia 16: 75-78

27. Jones IR, Owens DR, Luzio S, Hayes TM (1986) Gastric inhibitory polypeptide (glucose dependent insulinotropic polypeptide) concentrations and the hyperinsulinaemia of obesity. Diabetic Medicine 4: 367 (Abstract)

28. Dryburgh JR, Hampton SM, Morgan LM, Marks V (1980) C peptide induced inhibition of glucose dependent insulinotropic polypeptide release. Regul Pep 1: 28 (Abstract)

29. Larrimer JN, Mazzaferri EL, Cataland S, Mekhjian HS (1978) Effect of atropine on glucose stimulated gastric inhibitory polypeptide. Diabetes 27: 638-642

30. Baumert JE, Cataland S, Tetirick CE, Pace WG, Mazzaferri EL (1978) Effect of atropine on meal stimulated gastrin and gastric inhibitory polypeptide (glucose dependent insulinotropic polypeptide) release. J Clin Endocrinol Metal 31: 473-476
31. Nauck M, Stockmann F, Ebert R, Creutzfeldt W (1986) Reduced incretin effect in Type 2 (non-insulin dependent) diabetes. Diabetologia 29: 46-52

32. Jones IR, Owens DR, Moody AJ, Luzio SD, Morris T, Hayes TM (1987) The effects of glucose dependent insulinotropic polypeptide infused at physiological concentrations in normal subjects and Type 2 (non-insulin-dependent) diabetic patients on glucose tolerance and B-cell secretion. Diabetologia 30: 707-712

33. Paul AA, Southgate DAT (1985) The composition of foods 4th edn. McCance and Widdowson, London

Received: 14 November 1988

and in revised form: 3 April 1989

Dr. D.R. Owens

Diabetes Research Unit

Department of Medicine

University of Wales, College of Medicine

Heath Park

Cardiff CFA 4XN

UK 